\title{
An evaluation of the body composition, behaviours and attitudes of adolescent male sports-players to nutrition
}

\author{
M. Walsh ${ }^{1}$, L. Cartwright ${ }^{1}$, C. Corish ${ }^{1}$, S. Sugrue ${ }^{1}$ and R. Wood-Martin ${ }^{2}$ \\ ${ }^{1}$ School of Biological Sciences, Dublin Institute of Technology, Kevin St, Dublin 8, Republic of Ireland and \\ ${ }^{2}$ Irish Rugby Football Union, Landsdowne Road, Dublin 4, Republic of Ireland
}

Rugby union is a sport played by all ages in Ireland, from underage level right through to the senior representative squad. Senior schoolboy rugby players are aged approximately 15-18 years and compete in the Senior School's Cup throughout the academic year. The aim of the present study was to profile the body composition of a sample of adolescent male rugby players in Leinster, Republic of Ireland and to determine their nutritional behaviours and attitudes. Male subjects ( $n$ 203) were recruited from the senior rugby panel in six secondary schools in Leinster. Nutritional behaviours and attitudes were assessed using a self-administered questionnaire designed specifically for the study. Height, weight and estimated percentage body fat (PBF) using bioelectrical impedance (BC $418 \mathrm{MA}$; Tanita Corporation, Tokyo, Japan) were obtained for all 203 subjects. The Table presents anthropometric data obtained.

\begin{tabular}{lcccc}
\hline & Player position & $n$ & Mean & SD \\
\hline Weight $(\mathrm{kg})$ & Forward & 115 & $85.5^{*}$ & 10.8 \\
& Back & 85 & 75.9 & 8.03 \\
PBF & Forward & 84 & $14.7^{*}$ & 4.6 \\
& Back & 57 & 11.2 & 2.8 \\
Mean PBF of BMI category $\dagger:$ & & & \\
Normal weight & & 68 & 10.5 & 2.4 \\
Overweight & & 52 & 13.6 & 2.7 \\
Obese & 24 & 20.5 & 3.0 \\
\hline
\end{tabular}

Mean values were significantly different from those for the backs: $* P<0.05$. PBF was significantly different across all BMI categories: $† P<0.05$.

Although $35 \%$ and $14.8 \%$ of subjects were defined as overweight and obese respectively using BMI centile charts ${ }^{(1)}$, only fourteen players had PBF values higher than the recommended upper limit of $20 \%{ }^{(2)}$. Forwards were significantly taller, heavier and fatter than backs $(P<0.005$ for all). This finding is explained by the differing roles of forwards and backs in rugby. Forwards are involved in more physical collisions and tackles compared with backs who are involved in more high-intensity activities such as running ${ }^{(3)}$.

Alcohol consumption and dietary supplement use were practiced by $88 \%$ and $64 \%$ of these schoolboys respectively. Attitude to supplement use may be a predictor of behaviour as supplement users believed supplements were necessary to support training performance compared with non-supplement users $(P<0.001)$. Self-perception of body size did not predict dietary supplement use.

As expected, BMI had limited application as a measure of the body composition in adolescent rugby players. Behaviours and attitudes reported suggest that a rigorous evaluation of the health education materials currently available to adolescent rugby players, their coaches and parents is required. Nutrition education programmes devised for adolescent rugby players must, however, consider the specific requirements of the sport of rugby as well as the attitudes, beliefs and values that underlie the health-related choices of male adolescents.

1. Cole TJ, Freeman JV \& Preece MA (1995) Arch Dis Child 73, 25-29.

2. Mc Carthy HD, Cole TJ, Fry T et al. (2006) Int J Obes (Lond) 30, 598-602.

3. Roberts SP, Trewartha G, Higgitt RJ et al. (2008) J Sports Sci 26, 825-833. 